\title{
Czech Language
}

National Cancer Institute

\section{Source}

National Cancer Institute. Czech Language. NCI Thesaurus. Code C153875.

A West Slavic language that serves as the official language of the Czech Republic. 